\title{
Cloning and expression of porcine adiponectin, and its relationship to adiposity, lipogenesis and the acute phase response
}

\author{
S K Jacobi, K M Ajuwon, T E Weber, J L Kuske, C J Dyer ${ }^{1}$ and \\ M E Spurlock \\ Department of Animal Sciences, Comparative Medicine Program, Purdue University, West Lafayette, Indiana, USA \\ ${ }^{1}$ Monsanto Co., St Louis, Missouri, USA \\ (Requests for offprints should be addressed to M E Spurlock, Lilly Hall of Life Sciences, 915 W State Street, Purdue University, West Lafayette, Indiana \\ 47907-2054, USA; Email: spurloc0@purdue.edu)
}

\begin{abstract}
Adiponectin is an adipocyte-derived hormone that has been implicated recently in the regulation of inflammation in immunocytes, and in lipid metabolism and glucose homeostasis in liver, skeletal muscle and adipocytes. However, information in non-rodent models is limited. We have cloned and sequenced the porcine adiponectin open reading frame and evaluated the regulation of adiponectin in vivo following lipopolysaccharide (LPS) or E. coli administration. The porcine sequence shares approximately 88 , 86,85 and $83 \%$ homology with the dog, human, cow and mouse adiponectin respectively, and 79-83\% similarity with dog, human, cow and mouse proteins at the amino acid level, based on the translated porcine sequence and GenBank submissions for the other species. Relative serum adiponectin concentrations were not altered in pigs infused with E. coli, and mRNA expression in adipose
\end{abstract}

tissue was not responsive to LPS. However, analysis of serum from very lean vs a substantially fatter genotype of pig indicated that relative circulating adiponectin concentrations are higher $(P<0 \cdot 01)$ in the lean pigs than in the fatter genotype, and that the difference is established relatively early in the growth curve. Also, incubating pig adipocytes for $6 \mathrm{~h}$ with recombinant pig adiponectin resulted in an approximately $30 \%$ reduction $(P<0 \cdot 05)$ in lipogenesis compared with adipocytes under basal conditions and with those incubated in the presence of insulin. This is the first report in any species that adiponectin antagonizes the incorporation of glucose carbon into lipid in the adipocyte, and provides additional evidence that adiponectin acts as an autocrine regulatory factor to regulate energy metabolism.

Journal of Endocrinology (2004) 182, 133-144

\section{Introduction}

Adiponectin is a relatively new 'adipocytokine' that circulates in the blood as the mature protein (Arita et al. 1999), and as an apparent carboxy-terminal proteolytic cleavage peptide that has marked structural similarity to tumor necrosis factor (TNF)- $\alpha$ (Fruebis et al. 2001). Recombinant human adiponectin attenuates TNF- $\alpha$ expression and secretion by macrophages stimulated with lipopolysaccharide (LPS), and also reduces their phagocytic activity and stimulates apoptosis in certain myeolomonocytic cell populations (Yokota et al. 2000). Recent developments have also implicated adiponectin as a regulator of insulin sensitivity, glucose homeostasis and lipid metabolism. Both intact adiponectin and the globular cleavage peptide regulate energy metabolism in skeletal muscle (Fruebis et al. 2001, Tomas et al. 2002, Yamauchi et al. 2002) and liver (Berg et al. 2001, Combs et al. 2001, Yamauchi et al. 2001), albeit with different potencies; adiponectin causes weight loss, up-regulates fatty acid transporters, and stimulates fatty acid oxidation in skeletal muscle, and augments the suppression of glucose production by insulin in the liver. Furthermore, Wu et al. (2003) have shown a direct stimulatory effect of globular adiponectin on glucose uptake in primary rat adipocytes, and provided compelling evidence that this peptide attenuates the inhibition of insulin-stimulated glucose uptake by TNF- $\alpha$. Collectively, these regulatory actions across skeletal muscle, liver and adipose tissue would abrogate the insulin insensitivity and hyperglycemia common in rodent models of Type II diabetes.

In contrast with leptin, which is increased with body fat accretion and obesity, plasma concentrations of adiponectin are decreased in a number of altered metabolic states, including obesity (Arita et al. 1999), dyslipidemia (Matsubara et al. 2002), and Type II diabetes and coronary artery disease (Hotta et al. 2000). Recently, Fruebis et al. (2001) hypothesized that the reduction in circulating adiponectin that is associated with obesity is causally related to the excessive accumulation of body fat. Furthermore, Yamauchi et al. (2001) discovered that leptin and adiponectin were additive in their enhancement of the 
inhibition of glucose production by insulin in the liver of lipotrophic mice. Thus, the relationship between circulating adiponectin, leptin and adiposity in the pig, a rapidly emerging research model, is of considerable interest.

With these considerations in mind, our primary objectives were to test the hypotheses that (i) adiponectin exerts an anti-lipogenic action directly upon the pig adipocyte, and (ii) that serum adiponectin concentrations would be lower in a fatter genotype of pig vs a leaner genotype, whereas leptin would be higher. Also, the antiinflammatory actions of adiponectin indicate that the short-term regulation of adiponectin may be important during the acute phase response, and may relate to the regulation of metabolism and immune response pathways by pro-inflammatory cytokines. Consequently, our third objective was to determine whether serum adiponectin or mRNA expression is altered by bacterial infection or endotoxin challenge.

\section{Materials and Methods}

\section{Animals and adipocyte isolation}

Adipose tissue was obtained from male castrates weighing approximately $90-110 \mathrm{~kg}$, and freely consuming a nutritionally complete diet. The pigs were maintained according to protocols approved by the Purdue University Animal Care and Use Committee, and killed in the Purdue University abattoir according to USDA regulations. s.c. adipose tissue was removed from the dorsal depot located over the cervical spine, and transported in buffered saline $\left(37^{\circ} \mathrm{C}, 0.15 \mathrm{M} \mathrm{NaCl}, 10 \mathrm{mM}\right.$ Hepes, $\left.\mathrm{pH} 7 \cdot 4\right)$ to the laboratory. Adherent skeletal muscle was removed, and the tissue was cubed and sliced with a Stadie-Riggs microtome. Approximately $6-7 \mathrm{~g}$ sliced tissue were minced, rinsed with saline, and transferred to a flask containing $15 \mathrm{mg}$ collagenase $(100 \mathrm{U} / \mathrm{ml}$ final concentration) (Worthington BioChemical, Lakewood, NJ, USA). Following a 30-35 min digestion period, isolated adipocytes were washed through a $290 \mu \mathrm{m}$ screen with warmed Krebs-Ringer bicarbonate buffer ( $\mathrm{pH} 7 \cdot 4)$ containing $10 \mathrm{mM}$ Hepes, $5 \mathrm{mM}$ glucose, and 3\% BSA (Fraction V, essentially fatty acid free; Invitrogen Life Technologies, Carlsbad, CA, USA) to remove all other cell debris. The cells were resuspended in culture media (DMEM, Sigma D6780; Sigma, St Louis, MO, USA) with $3 \%$ BSA and $10 \mathrm{mM}$ Hepes at a final concentration of approximately $2 \times 10^{5}$ cells $/ \mathrm{ml}$ and aliquoted immediately into $15 \mathrm{ml}$ polypropylene scintillation vials for incubation.

\section{$R N A$ isolation}

Total RNA was extracted from cells as described by Chomczynski \& Sacchi (1987). Briefly, cells were homogenized in guanidinium thiocyanate, followed by the addition of sodium acetate. The samples were then extracted sequentially with water-saturated phenol and chloroform:isoamyl alcohol, and the aqueous fractions precipitated with isopropanol. After the second ethanol precipitation, the RNA pellets were resuspended in Tris$\mathrm{HCl}$ buffer $(\mathrm{pH} 8.0)$ and quantitative and qualitative measures obtained spectrophotometrically. In addition, the actual RNA concentration of sample was determined using the RiboGreen assay (Molecular Probes, Eugene, OR, USA) and the manufacturer's protocol.

\section{Cloning}

Degenerative primers from highly conserved regions of mouse and human adiponectin sequences were designed to amplify porcine adiponectin cDNA using long-distance PCR (forward primer: 5'-CTGTCAATTTCAGGGCT CAGG-3'; reverse primer: 5'-GGCGCAGAGGAAACA AATCAGACTAG-3'). The cDNA was cloned by amplifying a reverse-transcribed product of RNA extracted from isolated adipocytes from $90 \mathrm{~kg}$ pigs. A cDNA clone of about $1100 \mathrm{bp}$ contained a $732 \mathrm{bp}$ open reading frame (ORF) coding a 243 amino acid protein. The $1100 \mathrm{bp}$ product was cloned into the PCRII-TOPO vector (Invitrogen Life Technologies) for sequencing.

\section{Protein expression and purification}

The protein expression and purification was carried out in a commercial facility (C\&P Biotech Corp., Thornhill, ON, Canada). Briefly, DNA containing the coding region of mature porcine adiponectin was amplified by PCR, then subcloned into pET15b (Novagen, Madison, WI, USA) sites (NdeI and BamHI/BglII) to introduce an aminoterminal His-tag and thrombin cleavage site. Once the insertion of the gene was verified by DNA sequencing, the plasmid was transformed into BL21 (DE3) cells (Stratagene, La Jolla, CA, USA). The cells were grown in LB broth with $50 \mu \mathrm{g} / \mathrm{ml}$ of ampicillin in shaker flasks at $37^{\circ} \mathrm{C}, 200 \mathrm{~g}$, until the OD600 was $0 \cdot 7$. Thereafter, $1 \mathrm{mM}$ isopropyl- $\beta$-D-thiogalactoside was added for induction, and after $2 \mathrm{~h}$, the cells were harvested by centrifugation at $5000 \mathrm{~g}$ for $15 \mathrm{~min}$, and stored at $-80^{\circ} \mathrm{C}$. The cells were lysed in $50 \mathrm{mM}$ Tris $\mathrm{pH} 8 \cdot 0,500 \mathrm{mM} \mathrm{NaCl}, 1 \mu \mathrm{M}$ phenylmethysulfonyl fluoride, and sonicated with power level $8,30 \%$ duty cycle for $3 \mathrm{~min}$ with a Sonifer brand sonicator (VWR International, Bristol, CT, USA). The supernatant fraction from the lysate was harvested by centrifugation at $15000 \mathrm{~g}$ for $30 \mathrm{~min}$, and it was loaded onto a Ni-NTA agarose column (Qiagen, Valencia, CA, USA). The column was washed with $50 \mathrm{mM}$ Tris $\mathrm{pH} 8 \cdot 0$, $500 \mathrm{mM} \mathrm{NaCl}, 10 \mathrm{mM}$ imidazole, and then the protein was eluted with $250 \mathrm{mM}$ imidazole in the same buffer. Fractions containing the protein of interest were pooled and dialyzed overnight at $4{ }^{\circ} \mathrm{C}$ into $25 \mathrm{mM}$ Tris, $50 \mathrm{mM}$ $\mathrm{NaCl}, 2 \mathrm{mM} \mathrm{CaCl}_{2}, \mathrm{pH} 7 \cdot 5$, containing $1 \mathrm{U}$ thrombin 
(Calbiochem, San Diego, CA, USA) per mg of protein. The protein sample was further purified over an S75 column (Amersham Pharmacia Biotech, Piscataway, NJ, USA) with PBS to remove the thrombin and His-tag. The fractions containing the protein were pooled and dialyzed into PBS overnight. Prior to use, the recombinant protein was concentrated by evaporative drying. Amino-terminal sequencing of the recombinant protein was carried out to confirm the identity of the expressed protein. The globular domain was cloned and expressed similarly. Aminoterminal sequencing of this peptide confirmed its identity. The amino-terminal sequence of the recombinant cleavage product was obtained to confirm the identity of the expressed peptide. Endotoxin analysis was performed by a commercial laboratory (Cambrex, Inc., Walkersville, MD, USA) to verify the purity of the preparation.

\section{Northern blot analysis}

Total RNA was extracted as described above from isolated adipocytes. Adiponectin mRNA was measured by Northern blot analysis with a porcine adiponectin cDNA corresponding to a $\sim 320 \mathrm{bp}$ region from the ORF of porcine adiponectin. The porcine adiponectin cDNA template was obtained by RT-PCR procedures, and the PCR product was confirmed by sequence analysis. The antisense primer of adiponectin was added to the T7 promoter sequence $\left(5^{\prime}\right.$-GGATCCTAAT ACGACTC ACT ATAGGGAGG-3') to allow Northern probe transcription under the control of T7 polymerase. Radiolabeling of the probe was accomplished by in vitro transcription with T7 RNA polymerase in the presence of $\left[{ }^{32} \mathrm{P}\right] \mathrm{UTP}$ (NEN/Perkin Elmer, Boston, MA, USA). The probe was gel purified on a $5 \%$ acrylamide- $8 \mathrm{M}$ urea gel and eluted from the gel with probe elution buffer (Ambion, Austin, TX, USA) overnight. Northern blots were performed with $3 \mu \mathrm{g}$ total adipocyte RNA. Samples were transferred to nitrocellulose membranes (Perkin Elmer Life Sciences, Inc., Boston, MA, USA) crosslinked with u.v. light and baked for $2 \mathrm{~h}$ at $80^{\circ} \mathrm{C}$. Membranes were probed overnight, washed and exposed to X-ray film overnight. Autoradiographs were quantified by image analysis. Following autoradiography, the membranes were stripped in $0.1 \times \operatorname{SSC}(1.5 \mathrm{M} \mathrm{NaCl}, 0 \cdot 15 \mathrm{M}$ sodium citrate, $\mathrm{pH}$ $7 \cdot 0), 0 \cdot 5 \%$ SDS at $95{ }^{\circ} \mathrm{C}$ to remove probe and rehybridized with a RNA probe corresponding to $18 \mathrm{~S}$ rRNA. The abundance of the 18S rRNA was used to standardize adiponectin mRNA abundance.

\section{Lipogenesis}

For lipogenic determinations, six $2 \mathrm{ml}$ aliquots of cell suspension were added to $15 \mathrm{ml}$ polypropylene scintillation vials, gassed with $5 \% \mathrm{CO}_{2} / 95 \% \mathrm{O}_{2}$ and incubated for $6 \mathrm{~h}$ at $37^{\circ} \mathrm{C}$ in an environmentally controlled shaking incubator. Cells were treated with no hormone, $30 \mu \mathrm{g} / \mathrm{ml}$ full-length porcine adiponectin, $30 \mu \mathrm{g} / \mathrm{ml}$ cleaved porcine adiponectin or $1 \mathrm{mU} / \mathrm{ml}$ porcine insulin (Sigma I-5532). Vials also contained $0.75 \mu \mathrm{Ci} \quad\left[\mathrm{U}_{-}{ }^{14} \mathrm{C}\right]$ glucose (NEN/ Perkin Elmer) and incubation media was the same as described above. After the appropriate incubation periods, the reactions were terminated with the addition of $100 \mu \mathrm{l} 17 \%$ perchloric acid. Total lipid was extracted with Dole's reagent. Briefly, $5 \mathrm{ml}$ Dole's reagent, $3 \mathrm{ml}$ hexane and $4 \mathrm{ml}$ distilled $\mathrm{H}_{2} \mathrm{O}$ were added and mixed in each vial. The phases were allowed to separate and the upper phase recovered and evaporated at $70{ }^{\circ} \mathrm{C}$ overnight. Thereafter, $5 \mathrm{ml}$ scintillation cocktail were added to vials and the counts determined for calculation of lipogenic activity.

\section{SDS-PAGE and immunoblotting}

Sample proteins were separated by discontinuous SDSPAGE (Laemmli 1970) using a 3.75\% stacking gel and $12 \cdot 5 \%$ resolving gels and then transferred to nitrocellulose membranes. For all experiments in which serum adiponectin was quantified on a relative basis, the adiponectin protein was detected using a monoclonal anti-human adiponectin antibody (ANOC 9108) which has been described previously (Okamoto et al. 2000, Ouchi et al. 2000). Preliminary experiments established a range of dilutions for pig serum (1:5 to 1:40) over which adiponectin signal intensity was linear with our colorimetric detection system and image analysis. Furthermore, the antibody was validated for use with pig serum by competitive displacement of signal when a range of antibody dilutions (1:1000 to 1:20 000) were preincubated with an excess of recombinant pig protein. Colorimetric visualization was accomplished via alkaline phosphatase-linked secondary antibody (goat anti-mouse IgG; American Qualex, La Mirada, CA, USA), which was used at a dilution of 1:2000. Western blotting with the monoclonal antibody indicated a primary band at approximately $30 \mathrm{kDa}$. This band was quantified as adiponectin in all experiments based on the fact that the antibody is monoclonal and binds recombinant pig adiponectin, and on our determination that the serum signal is competitively displaced with excess recombinant pig adiponectin.

\section{Genotype comparison}

To determine whether higher relative serum adiponectin concentrations are associated with leaner genotypes of pigs, two genetic lines were compared across several ages. The pigs were maintained, and killed at the appropriate time, according to a protocol approved by the Purdue University Animal Care and Use Committee. Females were housed in individual pens and allowed free intake of diets that were nutritionally complete with respect to the age of the pig. Actual body weight was recorded and measures of s.c. backfat depth were taken at the tenth rib approximately 
$2 \mathrm{~cm}$ off the midline in the pigs killed at the selected time points (28, 56, 90 and 165 days of age). Relative serum adiponectin concentrations were determined by Western blot analysis with the monoclonal antibody as described above. Additionally, serum leptin was quantified by a pig-specific RIA that is based on a polyclonal antibody generated against a synthetic peptide designed per the amino acid sequence derived from translation of the pig leptin ORF, as we have reported previously (Bidwell et al. 1997). The peptide (LQGALQDMLRQLDLSPGC) was complexed to keyhole limpet hemocyanin and used to immunize rabbits. The antibody was affinity purified, validated by Western blot analysis of recombinant pig leptin and pig serum, and used for the RIA of serum leptin. Recombinant pig leptin $(4 \mu \mathrm{g})$ was radiolabeled $\left({ }^{125} \mathrm{I}\right)$ using chloramine-T and a $22 \mathrm{~s}$ reaction period. For the RIA, $200 \mu \mathrm{l}$ samples were assayed in duplicate. The range of accurate quantification was from 0.25 to $16 \mathrm{ng} /$ $\mathrm{ml}$. Excellent regression was obtained from 94 to $7 \%$ binding (based on the 0 standard), and the standard curve has excellent correlation (0.99) over the range of 0-16 ng/ $\mathrm{ml}$ leptin. Additionally, the recovery of a leptin standard (also prepared with recombinant pig leptin) that was added to a pooled internal standard averaged $112 \cdot 8 \%$, well within the acceptable range. Parallelism was confirmed by assaying different volumes of a pooled internal serum standard $(25,50,100,150$ and $200 \mu \mathrm{l}$ per tube), which produced concentration estimates that were acceptably similar (coefficient of variation $11.4 \%)$. The intra- and inter-assay coefficients of variation were $9 \cdot 7$ and $11.6 \%$ respectively. The data were analyzed using a mixed model analysis which tested the effects of genetic line and age, and the interaction of line and age. Mean comparisons were established using the pdiff procedure of SAS when protected by a significant F-test.

\section{E. coli challenge}

The pigs used in this study were obtained from a commercial genetics company (Pig Improvement Company, Inc., Franklin, KY, USA) and housed at the Purina Mills, Inc. Research Center, Gray Summit, MO, USA. The protocol was approved by the corporate animal care and use committee. Briefly, individually penned pigs (male castrates weighing approximately $70 \mathrm{~kg}$ ) were allotted to three treatment groups consisting of a control group that was allowed free feed intake, a feed-deprived group, and a group deprived of feed and infused i.v. with an E. coli isolate $\left(5 \times 10^{9} \mathrm{cfu}\right)$ that was cultured from pig feces and provided by the Veterinary Services Department, Purina Mills, Inc., St Louis, MO, USA. The control and feeddeprived groups were infused i.v. with the same volume $(10 \mathrm{ml})$ of sterile medium used to deliver the E. coli to the challenged group. Blood samples were obtained by jugular venipuncture from all pigs just prior to infusion, and at 6 , 12 and $24 \mathrm{~h}$ following infusion. Feed consumption and rectal temperatures were obtained at the time of blood sampling to confirm the induction of an innate immune response to the $E$. coli challenge. Relative serum adiponectin concentrations were assessed by Western blot analysis as described above and the data quantified by image analysis. Statistical analysis was performed using a mixed model analysis in which the effects of time (age) and treatment were tested, as was the interaction of time and treatment.

\section{LPS challenge in the presence and absence of exogenous leptin}

In a previous study, we examined the impact of leptin administration on specific components of the innate immune response to endotoxin in the pig. We thought it also of considerable interest to determine whether leptin or LPS regulated adiponectin expression in the adipose tissue of these pigs. In this experiment, 20 male castrates of a commercial genotype, and weighing approximately $44.5 \mathrm{~kg}$, were randomly assigned to one of four treatments $(n=5)$ : (i) pigs injected with vehicle and saline; (ii) pigs injected with recombinant human leptin (Eli Lilly and Co., Indianapolis, IN, USA), i.m. at a dose of $0.025 \mathrm{mg}$ leptin/kg body weight; (iii) pigs injected with LPS of E. coli origin (Sigma) at a dose of $20 \mu \mathrm{g} / \mathrm{kg}$ body weight; and (iv) pigs injected with both leptin and LPS. The LPS or vehicle was injected into the appropriate pigs at $1700 \mathrm{~h}$ on day 1 , and again at $0500 \mathrm{~h}$ on day 2. Leptin was injected at 0900,1500 and $2100 \mathrm{~h}$ on day 1 , and at $0500 \mathrm{~h}$ on day 2. All pigs were deprived of feed for the duration of the study after the initial LPS injection. At $0900 \mathrm{~h}$ on day 2, the pigs were killed and samples of s.c. adipose tissue collected and frozen in liquid nitrogen pending RNA extraction. The data were analyzed using a mixed model approach which accounted for the effects of LPS and leptin, and the interaction.

\section{Results}

\section{Cloning of porcine adiponectin ORF}

Using RT-PCR and adipocyte RNA, we cloned the porcine adiponectin ORF. The resulting nucleotide sequence, aligned with available sequences from selected species, is shown in Fig. 1A, and the translated amino acid sequence and alignments are presented in Fig. 1B. The ORF for porcine adiponectin was determined to be $732 \mathrm{bp}$ in length, and when translated, yields a protein of 243 amino acids. The identity between the porcine nucleotide sequence and the rhesus monkey, human, dog, cow, mouse and rat is $86,86,88,85,83$ and $82 \%$ respectively (Table 1 ), and at the amino acid level, the identity was $79-83 \%$, based on the GenBank translations of the mouse, cow, human and monkey adiponectin sequences. Northern blot analysis of adiponectin expression in adipose tissue and isolated adipocytes is shown in 
(A)

porcine_atn

human adn monkey_tidn mouse_adn

porcine_adn human act monkey_adn mouse_adn

porcine_adn human_edn monkey_adn mouse_adn

porcine_adn human_adn monkey adn mouse_adn

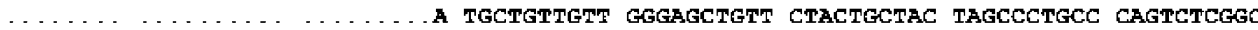

. CTGATTC CATACCAGAG GGGCTCAGGA TGCTGTTGCT GGGAGCTGTT CTACTGCTAT TAGCTCTGCC CGGGCATGAC $\ldots \ldots \ldots \ldots \ldots \ldots \ldots \ldots \ldots \ldots \ldots \ldots$. . . . . . . . . $\ldots$. TGGATCTGAC GACACCAAAA GGGCTCAGGA TGCTACTGTT GCAAGCTCTC CTGTTCCTCT TAATCCTGCC CAGTCATGCC

81 CAGGAA... . ACCACGAC TCAAGGGC. . CCGGAGTCC TGCTTCCCCT GCCCAAGGGG GCCTGCACAG GTTGGATGGC CACGAT... . ACCACAAC TCAAGGGC. . CCGGAGTCC TGCTTCCTCT GCCCAAGGGG GCCTGCACAG GTTGGATGGC GAAGTGACG TTACTACAAC TGAAGAGCTA GCTCCTGCTT TGGTCCCTCC ACCCAAGGGA ACTTGTGAG GTTGGATGGC

161

240

GGGTAFCCCA GGGCATCCTG GCCACAACGG TACCCCAGGC CGTGATGGCA GAGATGGCGT CCCTGGCGAG AAGGGTGAGA GGCCATCCCA GGCCATCCGG GCCATAATGG GGCCCCAGGC CGTGATGCCA GAGATGGCAC CCCTGETGAG AAGGGTGAGA AGCCATCCCA GGCCATCCAC GCCATAATGG GGTCCCAGGT CGTGATGCCA GAGATGGCAC CCCTGECGAG AAGGGTGAGA

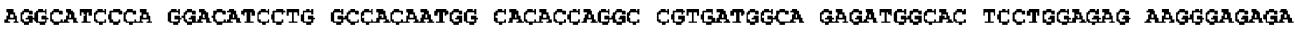

241

320

AGGAGATAC AGGPCTACT GGTCTAAGG GTGACACTGG GGATCTGGA GTGACTGGGG TTGAAGGTCC CCGAGGTPTC AAGGAGATCC AGGTCTTATT GGTCCTAAGG GAGACATCGG TGAAACCGGA GTACCCGGGG CTGAAGGTCC CCGAGGCTTT AAGGAGATCC AGGTCTTATC GGTCCTAAGG GAGACACTGG TGAAACTGGA GTAACCGGGG CTGAAGGTCC CCGAGGCTTT AMGGAGATG AGETCTCTT GGTCCTAAGG GTGAGACAGG AGATGTGGA ATGACAGGAG CTGAAGGGCC ACGGGGCTTC

321

400

porcine_adn human adn monkey_adn mouse_adn

CCAGGAATCC CGGGCAGAAA AGGAGAACCT GGAGAAAGCG CCTATGTCTA CCGTTCAGCA TTCAGTGTGG GCCTGGAGAC CCGGGATCC AAGGCAGGA AGGAGAACCT GGAGAAGGTG CCTATGTATA CCGCTCAGCA TTCAGTGTGG GATTGGAGAC CCGGGATCC AAGGCAGGAA AGGAGAACCT GGAGAGGTG CCTATGTATA CCGCTCAGCA TTCAGTGTGG GATTGAGAC

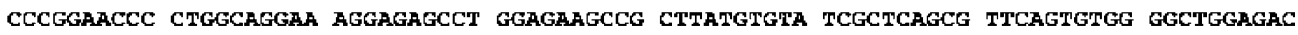

401

480

porcine_adn human_adn monkey_adn mouse_adn

porcine_tod humar_ad monkey_adn mouse adn

TCGGGTCACT GCCCCTAACA TGCCCATTCG CTTTACCAAG ATCTTCTACA ATCAGCAAAA CCACTATGAT GTCACCACTG TTACGTTACT ATCCCCAACA TGCCCATTCG CTTTACCAAG ATCTTCTACA ATCAGCAAAA CCACTATGAT GGCTCCACTG CTACGTTACT GTCCCCAACA TGCCCATTCG CTTTACCAAG ATCTTCTACA ATCAGCAAAA CCACTATGAT GGCTCCACTG CCGCGTCACT GTTCCCAATG TACCCATTCG CTTTACTAAG ATCTTCTACA ACCAACAGAA TCATMATGA GGCAGCACTG

481

560

GCAAATCCA CTGCAACATT CCTGGSCTGT ACTACTTCTC CTTCCACATC ACGGTCTACT TGAAGGATGT GAAGGTCAGC GTAAATCCC CTCCAACATT CCTGGGCTGT ACTACTTTGC CTACCACATC ACAGTCTATA TGAAGGATGT GAAGGTCAGC GTAATTCCA CTGCAACATT CCTGGGCTGT ACTACTTTGC CTACCACATC ACAGTCTATA TGAAGATGT GAAGTCAGC GCAAGTCTA CTGCAACATT CCGGGACTCT ACTACTTCTC TTACCACATC ACGGTGTACA TGAAAGATGT GAAGGTAGC

561

640

porcine_adn human_adn monkey adn mouse_ad

CTCTAAAGA AGGACAAGGC TGTACTCTTC CCCTACGACC AGTACCAGGA CAAGAATETG GACCAEGCCT CTGGCTCTGT CTCTRCAAGA AGGACAAGGC TATGCTCTTC ACCTATGATC AGTACCAGGA AAATAATGTG GACCAGGCCT CCGGCTCTGT CTCTTCAAGA AGGACAAGGC TATGCTCTTC ACCTATGACC AGTACCAGGA AAATAACGTG GACCAGGCCT CCGGCTCTGT CTCTTCAAGA AGGACAAGGC CGTTCTCTTC ACCTACGACC AGTATCAGGA AAAGAATGG GACCAGGCCT CTGGCTCTGT

641

720

porcine_adn human_adn monkey_adn mouse_adn

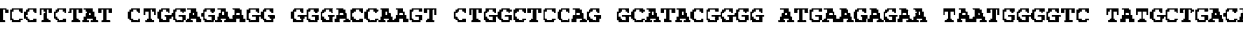
GCTCCTGCAT CTGGAGGTGG GCGACCAAGT CTGGCTCCAG GTGTATGGGG AAGGAGAGCG TAATGGACTC TATGCTGATA GCTCCTGCAT CTEGAGGTGG GCGACCAAGT CTGGCTCCAG GTGTATGGGG AAGGAGAGCG TAATGGACTC TATGCTGATA GCTCCTCCAT CTGGAGETGG GAGACCAAGT CTEGCTCCAG GTGTATGGGG ATGGGGACCA CAATGGACTC TATGCAGATA

721 BDO

porcine_ads human adn monkey_adn mouse_adn

ATGTCAATGA CTCCATCTTC ACAGGCTTCC TTCTCTACCA CAACATTGAA TGA.................. ATGACAATG CTCCACCTTC ACAGGCTTTC TTCTCTACCA TGACACCAAC TGATCACCAC TAACTCAGAG CCTCCTC.

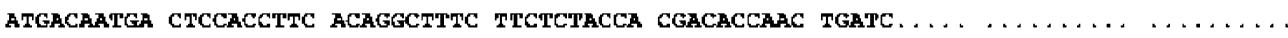
ACGTCAACGA CTCTACATTT ACTGGCTTTC TTCTCTACCA TGATACCAAC TGACTGCAAC TACCCATAGC CCATACA...

Figure 1 (A).

Fig. 2A and B respectively. In adipose tissue, we detected a predominant transcript of approximately $3.0 \mathrm{~kb}$, and transcripts of much lesser abundance at approximately $1 \cdot 7$, 1.3 and $0.9 \mathrm{~kb}$. In isolated adipocytes, the three smaller transcripts are absent, with the exception of one pig in which the smallest transcript was the predominant band, but the 3.0 and $1.3 \mathrm{~kb}$ transcripts were detected. Using Northern blot analysis and RT-PCR, we also confirmed that adiponectin expression is limited to the adipose tissue of the pig (data not shown).

Western blot analyses of pig serum with the monoclonal anti-human adiponectin antibody indicated the presence 
(B)

Porcine_adr Humar aर̄ंn Monkey_adn Mouse adr Bovine adn

Porcine_adn Humar acin Monkey_adn Mouse adr Bovire_adn

Porcine acts Human adr Monkey adn Mouse adr Eovire_adn

Forcine adn Human adn Monkey aㅐ Mouse adr Bovine_adn
$-1$

80 MLLLGAVLIL ILALSLGQET TEK. . . PGA LEPVPKGACA GMMAGIPGHP GHNGTPGRDG RDGVPGEKGE KGDTGLTGEK

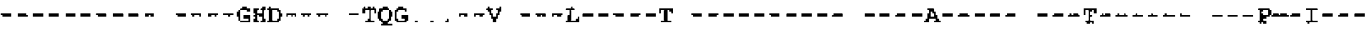

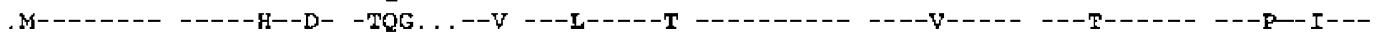

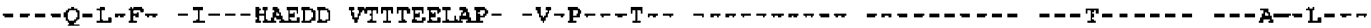

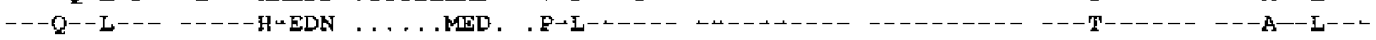

81

160 GDTGESGVTG VEGPRGFPGI PGRKGEPGES AYVYRSAFSV GLETRVTAPN MPIRFTKIFY NQQNHYDVTT GKFHCNIPGL

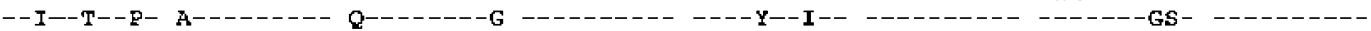

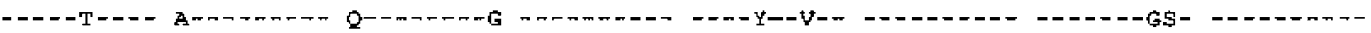

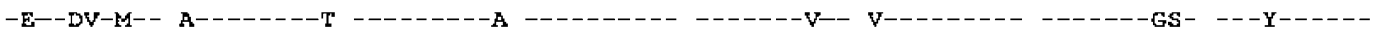

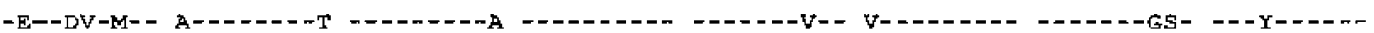

161 240 YYFSFHITVY LKDVKUSLYK KDKAVLFPYD OYQDKNVDQA SGSVLIYLEK GDQUWLOAYG DEENHGVYAD NVNDSIFTGF

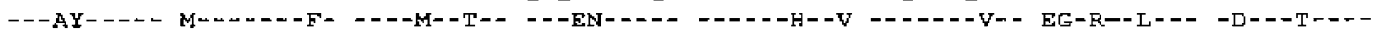

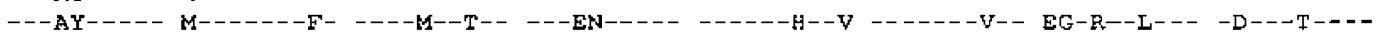

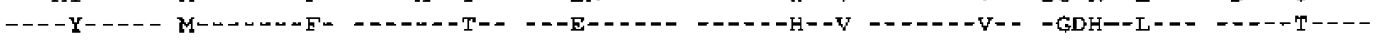

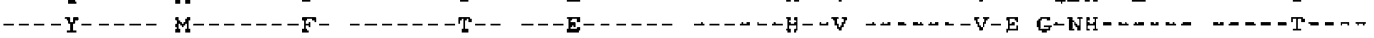

\section{1}

LLYHNIE.

---DTN.

- - - DTW.

- - DTF.

- - - - - VE

Figure 1 (B).

Figure 1 Nucleotide sequence and translation of porcine adiponectin (A). Comparison of porcine adiponectin (Adn) nucleotide sequence with human (NM_004797 gi4757759), monkey (AF404407 gi15213855) and mouse (BC028770 gi20381158). The percent identity of porcine nucleotide sequence with that of the species noted above is reported in Table 1. (B) The translated amino acid sequence of porcine Adn is compared with the translated human (NM_004797 gi4757759), monkey (AF404407 gi15213855), mouse (BC028770 gi20381158) and bovine (NP_777167 gi27807433). The amino acid sequence contains the predicted 18 amino acid secretory signal sequence, a series of Gly-X-Y repeats and a 36 amino acid region that is homologous to collagen VIII, collagen X and the C chain of C1q. The percent amino acid similarity of porcine Adn to other species is also reported in Table 1.

of two major proteins of approximately 30 and $35 \mathrm{kDa}$ (Fig. 3). The most abundant $30 \mathrm{kDa}$ protein is similar in size to the single band detected by the antibody in control human serum, and the less-abundant 34-35 kDa protein is similar to that reported previously for mice (YodaMurakami et al. 2001).

\section{Anti-lipogenic effect of adiponectin on porcine adipocytes}

The effect of adiponectin on lipogenesis and lipolysis were measured in isolated adipocytes in $6 \mathrm{~h}$ incubations. Basal

Table 1 Percent identity of porcine adiponectin with selected species at the nucleotide and amino acid level

\begin{tabular}{|c|c|c|}
\hline & Nucleotide (\% identity) & Amino acid (\% identity) \\
\hline \multicolumn{3}{|l|}{ Species } \\
\hline Dog & 88 & 88 \\
\hline Human & 86 & 82 \\
\hline Rhesus monkey & 86 & - \\
\hline Cow & 85 & 86 \\
\hline Mouse & 83 & 84 \\
\hline Rat & 82 & 82 \\
\hline
\end{tabular}

and insulin-stimulated lipogenesis, which were based on the incorporation of labeled glucose into extractable lipid, were reduced 28 and $30 \%$ respectively $(P<0 \cdot 05)$ by the full-length recombinant adiponectin (Fig. 4). However, the recombinant molecule representing the apparent cleavage peptide was ineffective at the same concentration (i.e. $30 \mu \mathrm{g} / \mathrm{ml}$ ). Neither the intact protein nor cleavage peptide altered lipolysis, assessed based on glycerol release from incubated adipocytes (data not shown).

\section{Regulation of serum adiponectin and $m R N A$ expression} in vivo

Feed restriction caused a small but insignificant increase $(P>0.05)$ in relative serum adiponectin concentrations vs the freely fed control. However, the concentration was not influenced by infusion with E. coli (Fig. 5). The latter finding was confirmed at the mRNA level using E. coli-derived LPS to mimic infection. In these pigs, the abundance of the adiponectin mRNA (Fig. 6) was not changed $4 \mathrm{~h}$ after a second injection of LPS that was administered $12 \mathrm{~h}$ after the initial injection, despite the induction of a transient febrile response and obvious 
(A)

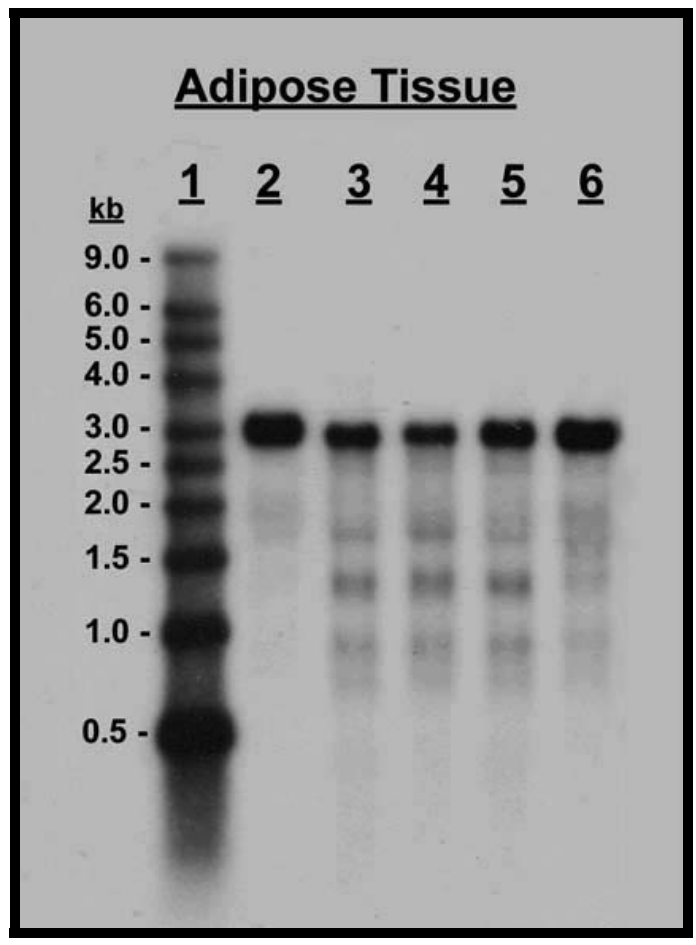

(B)

\section{Isolated Adipocytes}

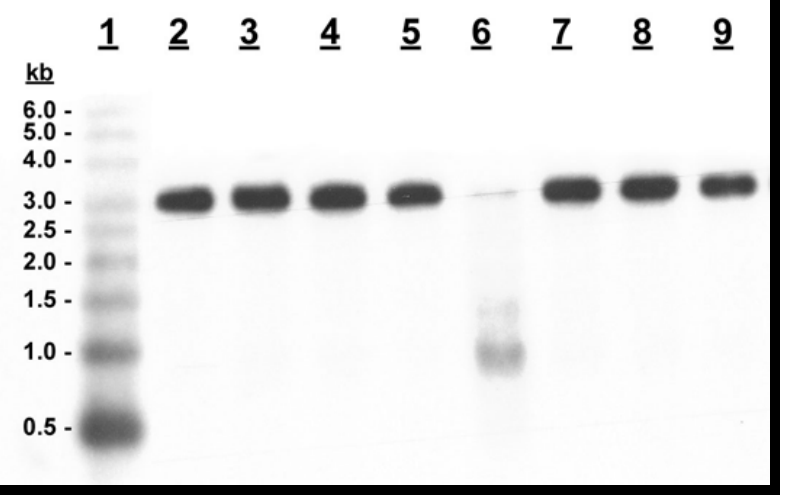

Figure 2 Northern blot analysis of adiponectin mRNA in pig adipose tissue (A) and isolated adipocytes (B). Total RNA was extracted from the adipose tissue or adipocytes isolated from the adipose tissue of multiple pigs; $5 \mu \mathrm{g}$ (adipose tissue) or $2.5 \mu \mathrm{g}$ (adipocytes) total RNA were probed on the Northern blot with the pig-specific adiponectin riboprobe as described in the Materials and Methods. Different pigs were used for adipose tissue vs adipocytes. The results indicate a predominate transcript for pig adiponectin that is approximately $3 \mathrm{~kb}$ in size. This transcript was used to establish relative differences among treatments in subsequent experiments. The specificity and origin of the smaller transcripts have not been characterized in any species.

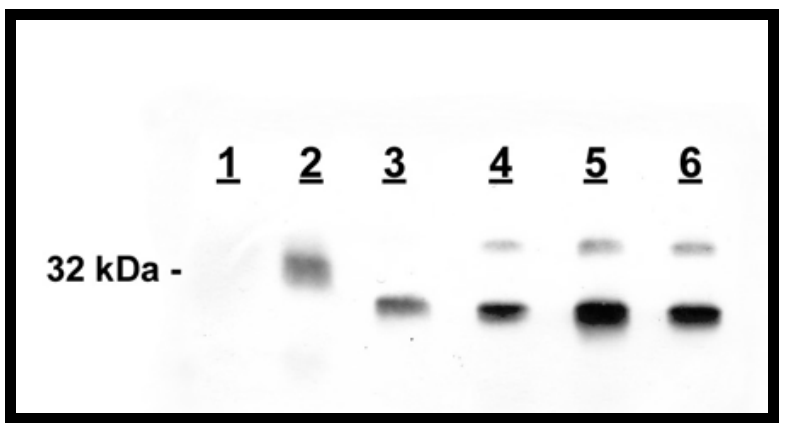

Figure 3 Western blot analysis of pig serum using a monoclonal anti-human adiponectin antibody described previously (ANOC 9108) (Okamoto et al. 2000, Ouchi et al. 2000). Lane 1 contained the BioRad Rainbow molecular weight markers (not visible in image of blot) and lane 2 is a human serum control. Lanes 3-6 are samples from individual pigs. The antibody detected a single predominant protein in human and pig serum at approximately 32 and $30 \mathrm{kDa}$ respectively, and also detected a larger protein of approximately 34-35 kDa in the serum of three pigs (lanes 4-6). The $30 \mathrm{kDa}$ band was quantified in pig serum samples by Western blotting and image analysis as described in the Materials and Methods.

sickness behavior. It is also notable that exogenous leptin did not alter the expression of adiponectin in pig adipose tissue $(P>0 \cdot 5)$, whether administered alone or in combination with the LPS.

\section{Serum adiponectin and leptin in lean vs a fatter genotype}

Serum samples were collected from pigs of two genetic lines with very different potentials for fat accretion, and subjected to Western blot analysis. As shown in Fig. 7A, relative serum adiponectin concentrations were similar in samples collected at 28 and 56 days of age. However, by 90 days of age, differences in adiposity (backfat depth, Fig. $7 \mathrm{~B})$ were reflected in serum adiponectin concentrations, with the leaner pigs having less backfat but higher $(P<0.05)$ relative adiponectin concentrations at 90 and at 165 days of age. In contrast, serum leptin concentrations were lower $(P<0 \cdot 01)$ in the lean line by 56 days of age (Fig. 7C), and the magnitude of the difference between lines increased with time (line $\times$ time, $P<0 \cdot 01)$. Identical differences were detected in the abundance of leptin mRNA in the adipose tissue of these two genotypes (not shown).

\section{Discussion}

Herein we report for the first time the sequence of the porcine adiponectin ORF, and provide the amino acid sequence of the protein inferred from translation of the nucleotide sequence. Both the coding region and the inferred amino acid sequence share substantial homology with those of other species. The adiponectin transcript in 


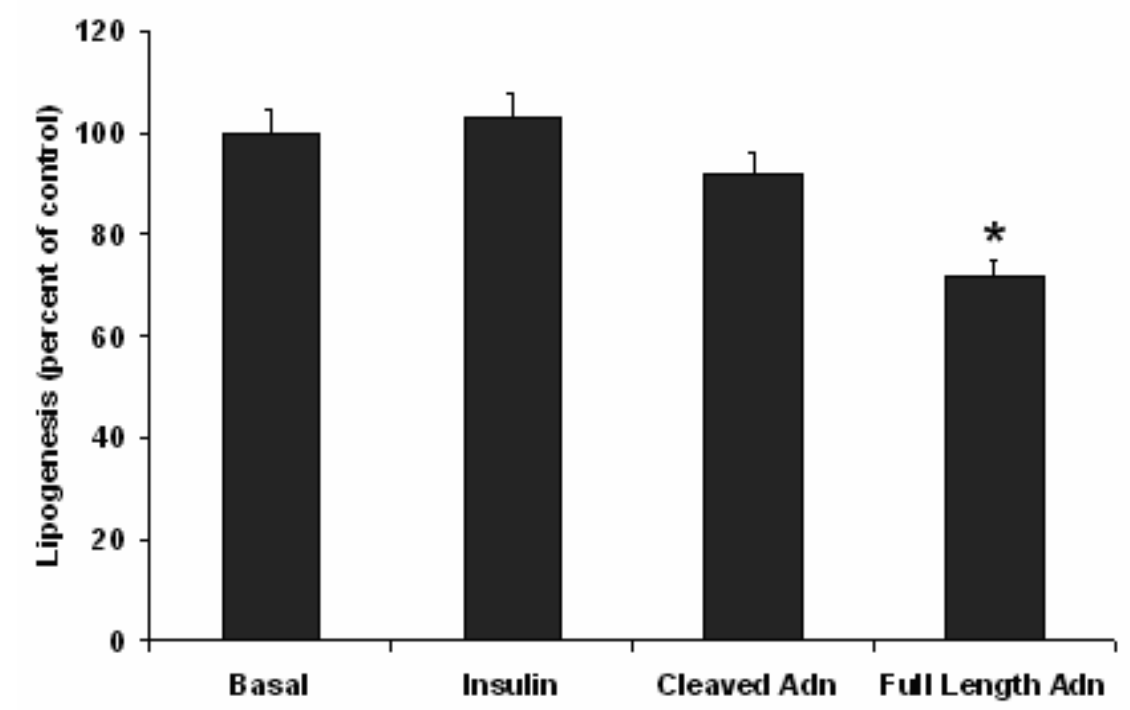

Figure 4 Regulation of lipogenesis in isolated pig adipocytes by recombinant pig adiponectin. Isolated pig adipocytes were incubated with porcine insulin $(1 \mathrm{mU} / \mathrm{ml})$, recombinant porcine globular adiponectin $(30 \mu \mathrm{g} / \mathrm{ml})$, or recombinant full-length porcine adiponectin $(30 \mu \mathrm{g} / \mathrm{ml})$. The data are expressed as a percentage of the basal treatment and represent five experiments performed with adipocytes isolated from different pigs. The asterisk indicates significant difference $(P<0.05)$ vs the basal control and insulin-stimulated treatments. Data reported as mean \pm S.E.

pig adipocytes is approximately $3.0 \mathrm{~kb}$, whereas there are three additional transcripts faintly detected in pig adipose tissue. Other publications have documented the presence of three similar transcripts in rat adipose tissue (Hu et al. 1996, Bensaid et al. 2003), whereas mouse adipose tissue expresses a single transcript (Hu et al. 1996). The identities of the smaller, less-abundant transcripts are not known.

Also consistent with previous findings (Scherer et al. 1995), the mRNA for adiponectin seems to be limited to the adipose tissue (adipocytes) of pigs. Although others have reported that adiponectin expression is induced in the liver of mice exposed to carbon tetrachloride, and in HepG2 cells cultured with interleukin (IL)-6 (YodaMurakami et al. 2001), we did not detect adiponectin mRNA in the liver of pigs injected with LPS (Northern blot analysis), or in primary pig hepatocytes stimulated with IL-6, even using RT-PCR (S K Jacobi, K M Ajuwon, T E Weber, J L Kuske, C J Dyer and M E Spurlock, unpublished observations). A monoclonal antihuman adiponectin antibody detected proteins of approximately 30 and $35 \mathrm{kDa}$ in pig serum. This smaller (30 kDa) protein is similar in size to the single protein detected in human serum by the monoclonal antibody, and was quantified in all experiments for which Western blot analysis was used to establish relative differences in circulating concentrations.

Others have reported that neither food deprivation nor leptin administration alters circulating adiponectin con- centrations in humans (Gavrila et al. 2003). Although numerically increased, the effect of feed deprivation was not significant in our E. coli sepsis experiment, nor was there an effect of leptin in the LPS experiment. Yokota et al. (2000) provided convincing evidence that adiponectin acts directly upon macrophages to attenuate proinflammatory cytokine (TNF- $\alpha$ ) expression and secretion into the medium, and to antagonize phagocytosis. Accordingly, we hypothesized initially that the acute regulation of adiponectin by inflammatory mediators in vivo would be such that transient increases in expression and secretion of adiponectin would potentiate its anti-inflammatory and metabolic actions by increasing the circulating protein concentration. In both the LPS and E. coli infusion models that we used, there were clear indications of the innate immune response (anorexia, fever, vomiting), and Webel et al. (1997) and Carroll et al. (2003) reported that the TNF- $\alpha$, IL- 6 and cortisol responses to LPS injection in the pig are relatively acute (i.e. peak within 4-6 h). Thus, our collective results at the mRNA and serum protein level indicate that the expression and secretion of adiponectin are not acutely regulated in vivo to alter the circulating protein concentration during infection. Our finding is largely consistent with a recent report in humans, in which circulating adiponectin concentrations were unchanged during endotoxemia (Keller et al. 2003). Recently, Tsao et al. (2002) determined that the oligomerization state of adiponectin regulates the biological activity and perhaps the effective concentration of adiponectin. Consequently, 


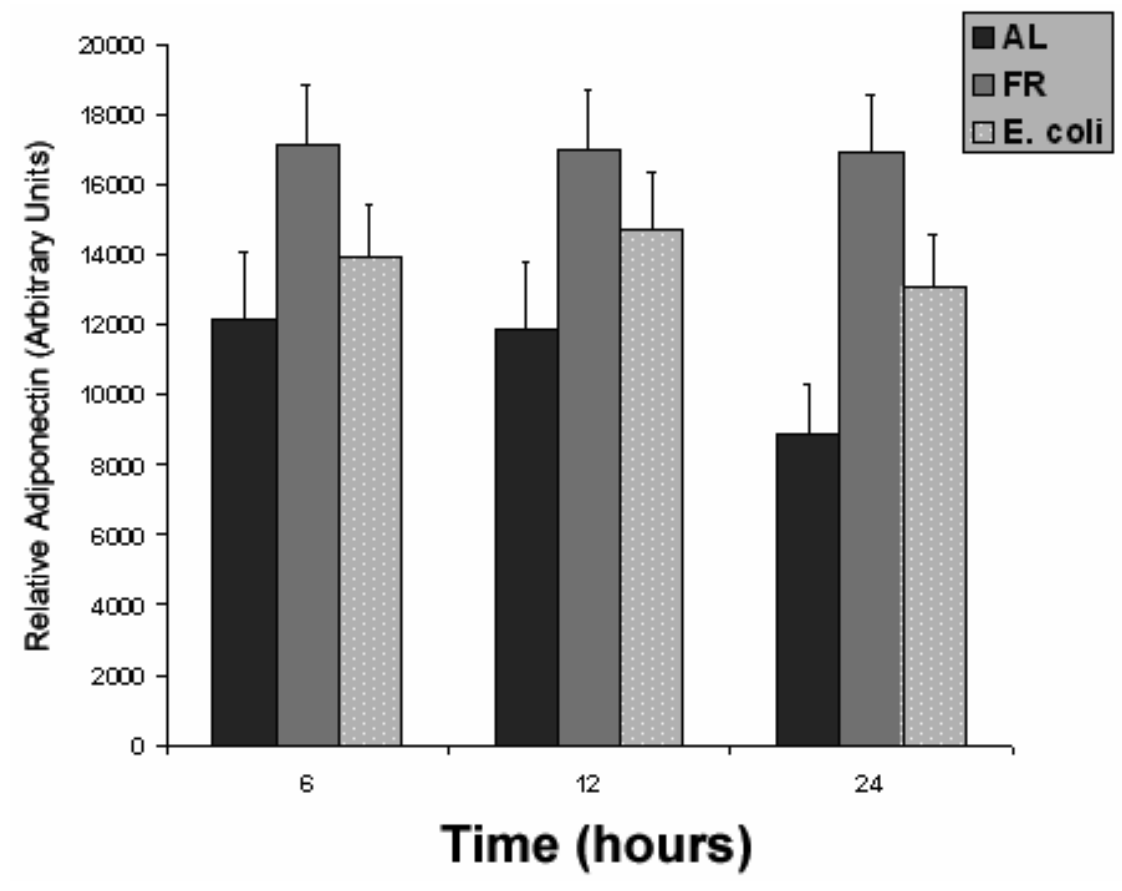

Figure 5 Relative serum concentrations of adiponectin in pigs challenged with an i.v. infusion of $E$. coli. Individually penned pigs (male castrates weighing approximately $70 \mathrm{~kg}$ ) were allotted to three treatment groups $(n=9)$ consisting of a control group that was allowed free feed intake (AL), a feed-deprived group (FR), and a group deprived of feed and infused i.v. with $5 \times 10^{9} \mathrm{cfu}$ of a fecal $E$. coli isolate (E. coli). Feed deprivation increased $(P<0.05)$ serum adiponectin, but there was no effect of $E$. coli infusion, nor was there an effect of time $(P>0 \cdot 05)$. Data reported as mean \pm S.E.

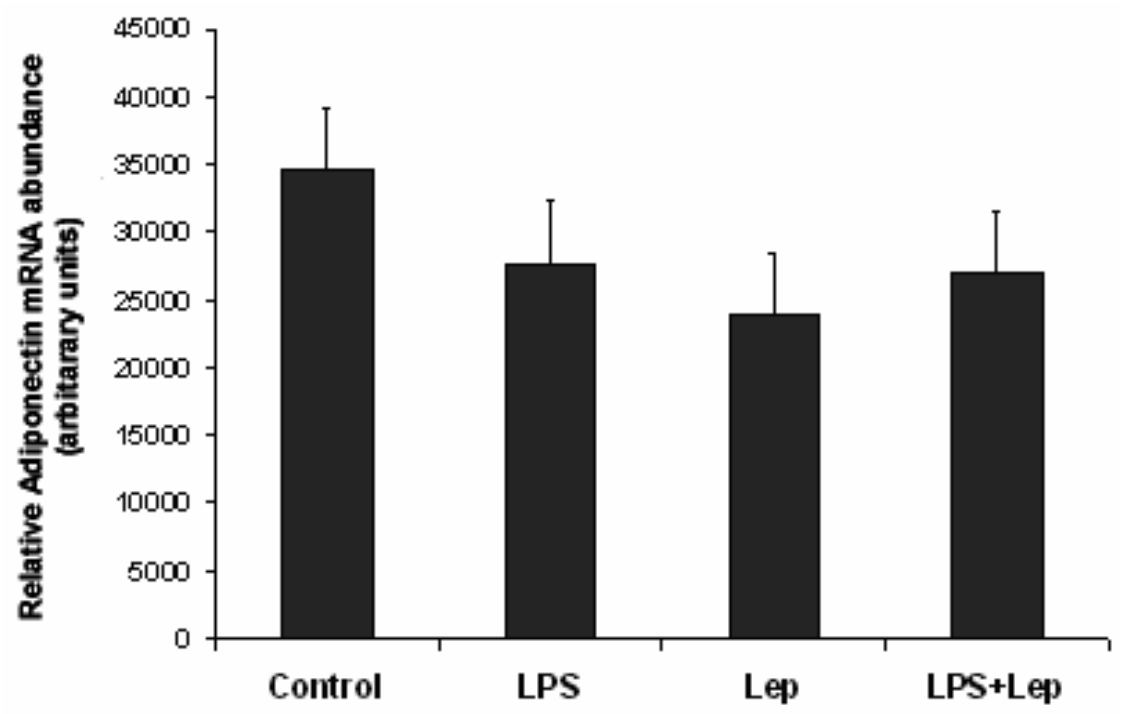

Figure 6 Relative adiponectin mRNA expression in pigs challenged with an i.m. injection of LPS, with and without exogenous leptin. Treatments were: injections of vehicle and saline (Control); E. coli-derived LPS at $20 \mu \mathrm{g} / \mathrm{kg}$ body weight (LPS); leptin at $0.025 \mathrm{mg} / \mathrm{kg}$ body weight (Lep); and the combination of LPS + leptin (LPS + Lep). The pigs $(n=5)$ were injected with leptin or vehicle at 0900,1500 and $2100 \mathrm{~h}$ on day 1 , and again at $0500 \mathrm{~h}$ on day 2 . The LPS injections were given at $1700 \mathrm{~h}$ on day 1 , and again at $0500 \mathrm{~h}$ on day 2 . There was no significant effect $(P>0 \cdot 05)$ of LPS or leptin, and there was no interaction. Data reported as mean \pm S.E. 
it seems likely that the anti-inflammatory activity of adiponectin is controlled through oligomerization, rather than through alterations in expression and secretion. It will also be of considerable importance to determine whether either of the adiponectin receptors identified by Yamauchi

(A)

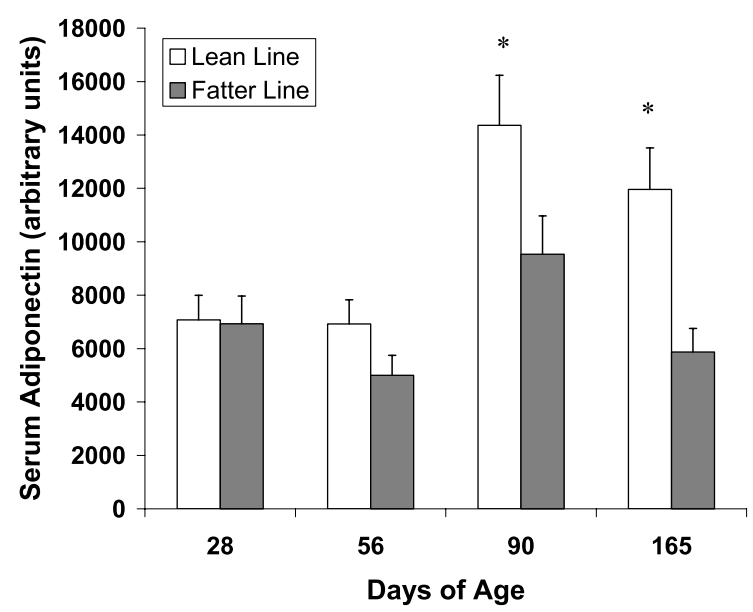

(B)

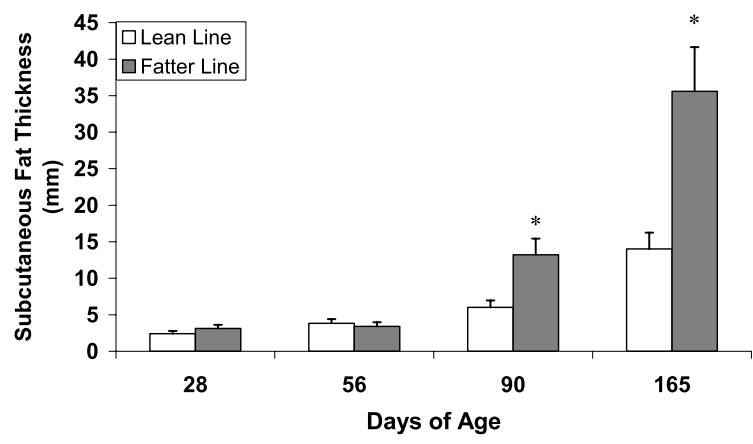

(C)

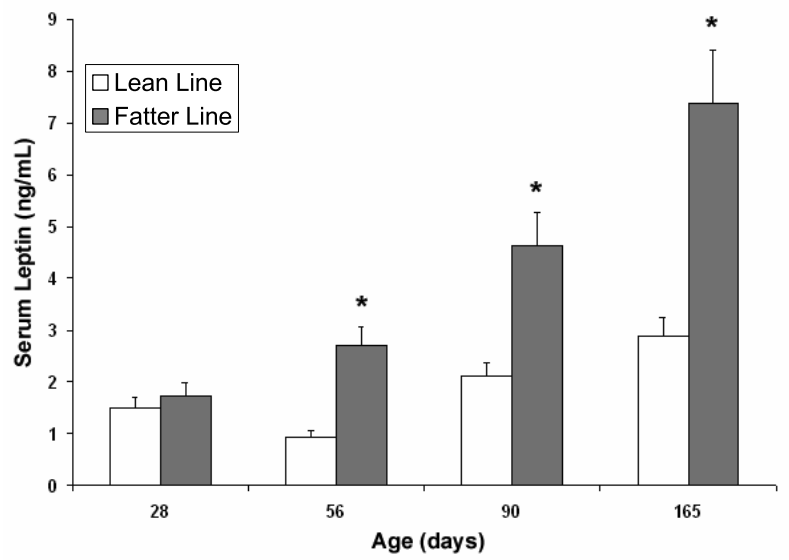

et al. (2003) is regulated in immune cells or peripheral tissues during the innate immune response.

Both adiponectin and the cleavage peptide regulate body weight and energy metabolism in skeletal muscle (Tomas et al. 2002, Yamauchi et al. 2002) and liver (Berg et al. 2001, Yamauchi et al. 2001), albeit with different potencies. Furthermore, Arita et al. (1999) determined that circulating adiponectin concentrations are lower in obese individuals, and in association with non-insulin-dependent diabetes, than in individuals with normal body composition and insulin sensitivity. Others have recently confirmed this finding in adolescent obesity (Weiss et al. 2003). We have extended these findings in two significant areas. First, we determined that lower adiponectin concentrations are associated with greater adiposity in the pig, a rapidly emerging biomedical research model, and that the lower serum adiponectin in the fatter genotype coincides with marked increases in serum leptin and in leptin mRNA in adipose tissue. This is of particular interest because the ratio of leptin to adiponectin has recently been proposed as an index of obesity in monkeys (Chen et al. 2003), and may have similar utility in other animal models. However, others have reported gender differences in circulating adiponectin in some models (Arita et al. 1999, Combs et al. 2003), and we had access only to females of the two genotypes used. Thus, it will be important to determine whether similar differences in adiponectin are associated with obesity in males. Secondly, we have shown for the first time in any species that intact adiponectin acts directly upon the adipocyte to suppress lipogenesis. Collectively, these findings support the hypothesis advanced by Fruebis et al. (2001) that the lower concentration of adiponectin observed in obese individuals is causally related to the excessive lipid accumulation. It is also notable that leptin administration did not alter the expression of adiponectin, despite the substantial increase (3-fold) in circulating leptin that is achieved within $24 \mathrm{~h}$ using the injection regimen and dose of leptin used in this study (Ajuwon et al. 2003). This finding corroborates a recent report in which leptin did not alter adiponectin status (Gavrila et al. 2003). Thus, it is unlikely that leptin

Figure 7 Relative serum adiponectin concentrations (A), s.c. backfat thickness (B) and serum leptin concentrations (C) in a lean vs a fatter genotype of pigs. At the ages (days) indicated, serum samples and measures of s.c. backfat depth were obtained from pigs $(n=4-5)$ representing the two genetic lines with greatly different potentials for fat accretion. The asterisks indicate significant differences $(P<0 \cdot 01)$ with respect to genotype. Additionally, there was an interaction between genotype and age such that the difference in backfat depth between lines increased with age $(P<0 \cdot 01)$. Serum leptin was determined using a pig-specific RIA as detailed in the Materials and Methods. The asterisks indicate significant differences $(P<0 \cdot 01)$ with respect to genotype $(n=4-5)$. There was also an interaction between genotype and time in that the magnitude of the difference in serum leptin between lines increased with time $(P<0 \cdot 01)$. Data reported as means \pm S.E. 
exerts a direct effect on adiponectin, despite the reciprocal regulation in association with obesity.

It is potentially of considerable importance that adiponectin reduced lipogenic activity in incubated adipocytes. It should be noted that the response of pig adipocytes to insulin is typically small or absent in the pig, in part because of significant release of adenosine from the adipoctye (Mills 2000). Although there was no effect of insulin in our experiments, adiponectin did reduce lipogenic activity relative to both basal and insulin-stimulated conditions. It is not yet clear whether adiponectin acts directly to counter the lipogenic effect of adenosine. However, Yamauchi et al. (2002) and Tomas et al. (2002) reported that activation of the $5^{\prime}$-AMP-activated protein kinase (AMPK) is central to the regulation of fatty acid oxidation and acetyl Co-A carboxylase activity by adiponectin in skeletal muscle. More recently, Wu et al. (2003) reported that globular adiponectin stimulated glucose transport in primary rat adipocytes cultures. This response was dependent upon the activation (phosphorylation) of AMPK, and was independent of critical factors in the insulin signaling pathway, including insulin receptor substrate-1 or Akt. Additionally, the increased activity of AMPK caused a deactivation of acetyl Co-A carboxylase, which would be expected to attenuate lipogenic activity. This seems paradoxical with the induction of peroxisome proliferator-activated receptor- $\gamma$ and adiponectin by thiazolidinediones (TZDs), which are insulin-sensitizing agents that promote lipogenic activity in adipose tissue, albeit it is important to consider the short-term nature of our experiments (hours) vs the longer-term experiments with TZD (Yu et al. 2002). It is also perhaps significant that marked increases in insulin sensitivity in adipose tissue with TZD administration, a phenomenon not yet demonstrated for adiponectin in adipocytes. In our experiments, the cleavage peptide did not reduce lipogenesis, as did the intact protein. It is possible that our recombinant cleavage peptide is less biologically active, and that higher concentrations are required to suppress lipogenesis.

In summary, we have confirmed herein that relative circulating adiponectin concentrations reflect differences in adiposity in the pig, and report for the first time that adiponectin acts directly upon isolated pig adipocytes to attenuate lipogenesis. Thus, the regulation of fat accretion by adiponectin may also include the direct regulation of de novo lipogenesis in the pig adipocytes. The mechanism by which adiponectin regulates lipogenesis, and the mechanisms which culminate in lower concentrations of adiponectin in obese individuals may offer new targets for alleviating obesity. We have also shown that adiponectin is not acutely regulated by pro-inflammatory cytokines, in vitro, or during the acute phase response in vivo. These findings indicate that the anti-inflammatory actions of adiponectin are not regulated by transient changes in expression and secretion of adiponectin.

\section{Acknowledgements}

We are grateful to Monsanto Choice Genetics, Inc., St Louis, MO, for providing the two genotypes of pigs used in the adiposity study. We also express our appreciation to Dr Brian Richert and his staff, Purdue University, for help with sample collection and backfat measurements, and to Drs Isao Takahashi and Tohru Funahashi, Osaka University Graduate School of Medicine, Osaka, Japan, for providing the antibody to human adiponectin. In addition, we thank Dr Mark Heiman and Eli Lilly \& Co., Indianapolis, IN for providing the leptin analog.

\section{Funding}

The authors received partial funding from the Purdue Research Foundation, Biotechnology Research \& Development Corporation, and Monsanto Choice Genetics, Inc., and declare that there is no conflict of interest that would prejudice impartiality.

\section{References}

Ajuwon KM, Kuske JL, Ragland DM, Adeola L, Hancock DL, Anderson DB \& Spurlock ME 2003 The regulation of IGF-1 by leptin in the pig is tissue specific and independent of changes in growth hormone. Journal of Nutritional Biochemistry 14 522-530.

Arita Y, Kihara S, Ouchi N, Takahashi M, Maeda K, Miyagawa J, Hotta K, Shimomura I, Nakamura T, Miyaoka K et al. 1999 Paradoxical decrease of an adipose-specific protein, adiponectin, in obesity. Biochemical and Biophysical Research Communications 257 79-83.

Bensaid M, Gary-Bobo M, Esclangon A, Maffrand JP, Le Fur G, Oury-Donat F \& Soubrie P 2003 The cannabinoid CB1 receptor antagonist SR141716 increases Acrp30 mRNA expression in adipose tissue of obese $f a / f a$ rats and in cultured adipocyte cells. Molecular Pharmacology 63 908-914.

Berg AH, Combs TP, Du X, Brownlee M \& Scherer PE 2001 The adipocyte-secreted protein Acrp30 enhances hepatic insulin action. Nature Medicine 7 947-953.

Bidwell CA, Ji SQ, Frank GR, Cornelius SG, Willis GM \& Spurlock ME 1997 Cloning and expression of the porcine obese gene. Animal Biotechnology 8 191-206.

Carroll JA, Gaines AM, Spencer JD, Allee GL, Kattesh HG, Roberts MP \& Zannelli ME 2003 Effect of menhaden fish oil supplementation and lipopolysaccharide exposure on nursery pigs. I. Effects on the immune axis when fed diets containing spray-dried plasma. Domestic Animal Endocrinology 24 341-351.

Chen Y, Ogawa H, Narita H, Ohtoh K, Yoshida T \& Yoshikawa Y 2003 Ratio of leptin to adiponectin as an obesity index of cynomolgus monkeys (Macaca fascicularis). Experimental Animals $\mathbf{5 2}$ 137-143.

Chomczynski P \& Sacchi N 1987 Single-step method of RNA isolation by guanidinium thiocyanate-phenol-chloroform extraction. Analytical Biochemistry 162 156-159.

Combs TP, Berg AH, Obici S, Scherer PE \& Rossetti L 2001 Endogenous glucose production is inhibited by the adipose-derived protein Acrp30. Journal of Clinical Investigation 108 1875-1881.

Combs TP, Berg AH, Rajala MW, Klebanov S, Iyengar P, Jimenez-Chillaron JC, Patti ME, Klein SL, Weinstein RS \& 
Scherer PE 2003 Sexual differentiation, pregnancy, calorie restriction, and aging affect the adipocyte-specific secretory protein adiponectin. Diabetes 52 268-276.

Fruebis J, Tsao TS, Javorschi S, Ebbets-Reed D, Erickson MR, Yen FT, Bihain BE \& Lodish HF 2001 Proteolytic cleavage product of 30-kDa adipocyte complement-related protein increases fatty acid oxidation in muscle and causes weight loss in mice. PNAS $\mathbf{9 8}$ 2005-2010.

Gavrila A, Chan JL, Yiannakouris N, Kontogianni M, Miller LC, Orlova C \& Mantzoros CS 2003 Serum adiponectin levels are inversely associated with overall and central fat distribution but are not directly regulated by acute fasting or leptin administration in humans: cross-sectional and interventional studies. Journal of Clinical Endocrinology and Metabolism 88 4823-4831.

Hotta K, Funahashi T, Arita Y, Takahashi M, Matsuda M, Okamoto Y, Iwahashi $\mathrm{H}$, Kuriyama H, Ouchi N, Maeda K et al. 2000 Plasma concentrations of a novel, adipose-specific protein, adiponectin, in type 2 diabetic patients. Arteriosclerosis, Thrombosis, and Vascular Biology 20 1595-1599.

Hu E, Liang P \& Spiegelman BM 1996 AdipoQ is a novel adipose-specific gene dysregulated in obesity. Journal of Biological Chemistry 271 10697-10703

Keller P, Moller K, Krabbe KS \& Pedersen BK 2003 Circulating adiponectin levels during human endotoxaemia. Clinical and Experimental Immunology 134 107-110.

Laemmli UK 1970 Cleavage of structural proteins during the assembly of the head of bacteriophage T4. Nature 227 680-685.

Matsubara M, Maruoka S \& Katayose S 2002 Decreased plasma adiponectin concentrations in women with dyslipidemia. Journal of Clinical Endocrinology and Metabolism 87 2764-2769.

Mills SE 2000 Regulation of porcine adipocyte metabolism by insulin and adenosine. Journal of Animal Science 77 3201-3207.

Okamoto Y, Arita Y, Nishida M, Muraguchi M, Ouchi N, Takahashi M, Igura T, Inui Y, Kihara S, Nakamura T et al. 2000 An adipocyte-derived plasma protein, adiponectin, adheres to injured vascular walls. Hormone and Metabolism Research 32 47-50.

Ouchi N, Kihara S, Arita Y, Okamoto Y, Maeda K, Kuriyama H, Hotta K, Nishida M, Takahashi M, Muraguchi M et al. 2000 Adiponectin, an adipocyte-derived plasma protein, inhibits endothelial NF- $\mathrm{\kappa B}$ signaling through a cAMP-dependent pathway. Circulation 102 1296-1301.

Scherer PE, Williams S, Fgliano M, Baldini G \& Lodish HF 1995 A novel serum protein similar to $\mathrm{C} 1 \mathrm{q}$, produced exclusively in adipocytes. Journal of Biological Chemistry 27 26746-26749.

Tomas E, Tsu-Shuen T, Asish KS, Murrey HE, Zhang CC, Itani SI, Lodish HF \& Ruderman NB 2002 Enhanced muscle fat oxidation and glucose transport by ACRP30 globular domain: acetyl-CoA carboxylase inhibition and AMP-activated protein kinase activation. PNAS 99 16309-16313.
Tsao TS, Murrey HE, Hug C, Lee DH \& Lodish HF 2002 Oligomerization state-dependent activation of NF-kappa B signaling pathway by adipocyte complement-related protein of $30 \mathrm{kDa}$ (Acrp30). Journal of Biological Chemistry 277 29359-29362.

Webel DM, Finck BN, Baker DH \& Johnson RW 1997 Time course of increased plasma cytokines, cortisol, and urea nitrogen in pigs following intraperitoneal injection of lipopolysaccharide. Journal of Animal Science 75 1514-1520.

Weiss R, Dufour S, Groszmann A, Petersen K, Dziura J, Taksali SE, Shulman G \& Caprio S 2003 Low adiponectin levels in adolescent obesity: a marker of increased intramyocellular lipid accumulation. Journal of Clinical Endocrinology and Metabolism 88 2014-2018.

Wu X, Motoshima H, Mahadev K, Stalker T, Scalia R \& Goldstein B 2003 Involvement of AMP-activated protein kinase in glucose uptake stimulated by the globular domain of adiponectin in primary rat adipocytes. Diabetes 52 1355-1363.

Yamauchi T, Kamon J, Waki H, Terauchi Y, Kubota N, Hara K, Mori Y, Ide T, Murakami T, Tsuboyama-Kasaoka N et al. 2001 The fat-derived hormone adiponectin reverses insulin resistance associated with both lipoatrophy and obesity. Nature Medicine 7 941-946.

Yamauchi T, Kamon J, Minokoshi Y, Ito Y, Waki H, Uchida S, Yamashita Si, Noda M, Kita S, Ueki K et al. 2002 Adiponectin stimulates glucose utilization and fatty-acid oxidation by activating AMP-activated protein kinase. Nature 8 1288-1295.

Yamauchi T, Kamon J, Ito Y, Tsuchida A, Yokomizo T, Kita S, Sugiyama T, Miyagishi M, Hara K, Tsunoda M et al. 2003 Cloning of adiponectin receptors that mediate antidiabetic metabolic effects. Nature 423 762-769.

Yoda-Murakami M, Taniguchi M, Takahashi K, Kawamata S, Saito K, Choi-Miura NH \& Tomita M 2001 Change in expression of GBP28/adiponectin in carbon tetrachloride-administrated mouse liver. Biochemical and Biophysical Research Communications 285 372-377.

Yokota T, Oritani K, Takahashi I, Ishikawa J, Matsuyama A, Ouchi N, Kihara S, Funahashi T, Tenner AJ, Tomiyama Y et al. 2000 Adiponectin, a new member of the family of soluble defense collagens, negatively regulates the growth of myelomonocytic progenitors and the functions of macrophages. Blood 96 1723-1732.

Yu JG, Javorschi S, Hevener AL, Kruszynska YT, Norman RA, Sinha M \& Olefsky JM 2002 The effect of thiazolidinediones on plasma adiponectin levels in normal, obese, and type 2 diabetic subjects. Diabetes 51 2968-2974.

Received in final form 10 February 2004

Accepted 27 February 2004

Made available online as an

Accepted Preprint 11 March 2004 